\title{
Urban drainage and sustainable cities: how to achieve flood resilient societies?
}

\author{
G. La Loggia ${ }^{1}$, C. M. Fontanazza ${ }^{1}$, G. Freni ${ }^{2}$, V. Notaro ${ }^{1}$, \\ E. Oliveri ${ }^{1} \&$ V. Puleo ${ }^{1}$ \\ ${ }^{I}$ Dipartimento di Ingegneria Civile, Ambientale e Aerospaziale, \\ Università degli Studi di Palermo, Palermo, Italy \\ ${ }^{2}$ Facoltà di Ingegneria ed Architettura, Università "Kore" di Enna, \\ Cittadella Universitaria, Enna, Italy
}

\begin{abstract}
This paper tries to describe the main developments of urban flood forecasting and modelling. Currently, several new technologies are available for flood monitoring, modelling and mitigation and several paradigms suggest the adoption of greener approaches to urban storm water management. These tools and new approaches can be easily adaptable to new developments where the entire urban drainage system can be suited to follow a more sustainable way to drain storm water. The challenge for the future is instead aimed to apply this new philosophy to existing urban areas where the application of new tools and technologies requires high costs and such approaches have to be prepared by constructing a flood resilient society by means of education and capillary information.
\end{abstract}

Keywords: urban flooding, storm water management, urban drainage modelling, flood mitigation.

\section{Introduction}

Flash floods, some of which recently occurred in Italy and Europe $(2010,2011)$, have raised a common concern about urban drainage planning and the consideration that urban settlements insisting on a hydrogeological risk area need special actions both from a structural and non structural point of view. The entity of damage and the cost of structural measures moved the discussion on the sustainability of the present urban development paradigms. Following 
Novotny [1], a new fifth paradigm emerges from past successes and failures of the current and previous paradigms of controlling urban pollution and floods. Current systems are not resilient to large (extreme) precipitation events that are expected to increase as a result of forecasted global warming (IPCC [2]). This is mainly due to the fact that, for different reasons, planners and engineers have been forced into a cycle of implementing ever increasing imperviousness, larger interceptors and tunnels, longer transmission distances for water and wastewater, and lining, fencing off and burying the urban streams. The paradigm proposed by Novotny [1] is based on the premises that urban waters are the lifeline of cities and the focus of the movement towards more sustainable and emerging "green" cities. It introduces the green city concepts coming up with a new approach to drainage that would mimic nature and the pre-development hydrology. The new drainage will make a switch from strictly engineered systems (sewers) to ecologic systems (rain gardens, surface wetlands, ponds restored, etc.) (Hill [3], Ahern [4]).

Unfortunately this paradigm is not applicable everywhere: environmental restoration of urban areas is achievable when a society is culturally prepared and oriented to achieve a sustainable and green economy. Most of the cities in the world have a long track of history, and it is economically unfeasible to transform old and historical cities into green and more sustainable ones from the urban drainage viewpoint. In these cases, a sixth paradigm has to be introduced: as little can be done to mitigate heavy floods within the cities from a structural viewpoint, then the cities and the society have to become resilient to floods! This new paradigm is not conflicting with the previous one but it can be considered propaedeutic to its application in all that cases where a society reformation is needed before effective actions can be carried out to reach green cities. New developments, especially the ones neighbouring the existing cities, have to be sustainable and green, introducing also the concept of hydrologic invariance: this means that the area, once developed, has to mimic nature and the predevelopment hydrology, as stated by the fifth paradigm.

A technologic example oriented to the achievement of the fifth paradigm is given by the city of Seoul: an "areal" approach of managing rainwater has been formulated in that context by storing rainwater in small but numerous tanks; peak runoff is reduced while the time to peak flow is retarded (Han and Park [5]). After the rainfall, the relatively clean water stored in the tanks is used for non-drinking purposes resulting in water conservation. Monitoring and management of multiple rainwater tanks in whole city area, coupled with modern Information Technologies, has been found to be a powerful solution to mitigate the damage caused by urban flooding.

When such measures cannot be sustainably taken, an initial intervention on society is needed to increase its resilience and to make the concept of green cities more acceptable, taking precautionary measures that can reduce householder vulnerability, either before an event or by reactive adaptation during an event (Grothmann and Reusswig [6]). Literature shows that there is significant evidence that householders living in natural hazard areas often fail to act, or do little to lessen their risk of death, injury or property damage thus disproving the 
common idea that populations subjected to continuous risk are more prepared to face risky situations (Siegrist and Gutscher [7]). Harvatt et al. [8] have, for the first time, confirmed the complexity of factors underlying householder understanding and response to natural events. Even in high-risk areas, a lack of direct personal experience of flood events serves to attenuate understanding and to constrain motivation to take personal action.

Cities are becoming "smarter" and the huge amount of information flowing in a city network has to be used for multiple purposes: so investing in the 'digital city' is one more way of improving the preparation for natural disasters. In this respect, the application of hydroinformatics technologies in urban water systems plays a vital role. Increasingly, city managers are turning to the collection, archiving and analysis of data for their urban areas, especially through facilities offered by advanced geographic information systems (GIS) and remote sensing. Properly presented GIS maps of areas at risk become important means of communicating information on potential natural disasters at, say, public meetings or over the internet. Underground cable networks make the collection and presentation of real-time data more feasible. These measurements, coupled with remote sensing of land use and terrain levels, forecasts of rainfall based on weather radar and ensemble predictions from global circulation of the atmosphere and associated local area models, routine asset inspections and maintenance, and stake-holder and customer reports, can help to provide, even in real time, a digital overview of the risks associated with potential disasters. In order to assess risk however, it is necessary to generate scenarios of the possible initiation of disasters coupled with their consequences in the light of different control and mitigation actions. (Price and Vojinovic [9]).

\section{Urban drainage city planning: state of the art}

In the past, the basic philosophy to minimize flood risk in urban areas has been based on the reduction of urban flooding by massive pipe network re-design campaigns improving the drainage capability of the system (building bigger pipes, improving surface collection system, etc.). Whilst this approach is successful in eliminating local flooding problems, the increased volumes and peak flows determined by urbanization often cause downstream flooding problems together with pollution and erosion of natural receiving water bodies. Moreover, this approach is usually unpractical and anti-economical when dealing with large and complex drainage systems or with the older networks in strongly urbanized areas, such as the centre of some ancient municipalities. In such situations, sewer systems are often surcharged by storm water and flooding occurs even with frequent rainfalls.

In the framework defined by European Directives on environmental protection such as Water Framework Directive 2000/60 (Council Directive $91 / 271 / \mathrm{EEC}$ on water preservation and Directive $2007 / 60 / \mathrm{EC}$ on the assessment and management of flood risks), limitations have been fixed for defining the correct behaviour of an urban drainage system and the acceptability of their discharges in the environment. These limitations have relevant implications in 
urban drainage city planning defining criteria for designing, rehabilitating and planning of urban drainage systems putting the accent on the concept of "risk of failure" as the key point for analysing and comparing drainage systems.

On the basis of the previous considerations, new design approaches, based on the concept of hydrologic invariance, have been proposed introducing more natural and less invasive methods for retaining and/or disposing of surface water runoff. According to this new approach, many storm water retrofit practices (BMP's) have been proposed along with other available watershed restoration strategies for reducing pollutants, restoring habitat and stabilizing stream morphology as part of a holistic watershed restoration program. Namely, storm water retrofits consist of a series of structural storm water practices, such as infiltration and storage ones, designed to reduce the peak flow of runoff, mitigate erosive flows, reduce pollutants in storm water runoff, and promote conditions for improved aquatic habitat. Such solutions require population acceptance because they require installation costs, maintenance and control that can be perceived as excessive and unmotivated measures simply aimed to landscape amelioration. Therefore, population living in flood prone areas have to be firstly resilient to urban flooding before structural measure can be considered as an acceptable cost.

\section{Analysis of recent storm events in Europe}

Annual precipitation trends in the 20th century showed an increase in northern Europe (10-40\%) and a decrease in some parts of southern Europe (up to 20\%). For Europe as a whole, the intensity of precipitation extremes such as heavy rain events has increased in the past 50 years, even for areas with a decrease in mean precipitation such as central Europe and the Mediterranean. Heavy precipitation events are projected to continue to become more frequent (IPCC [2]).

High precipitation extremes can result in fast flash floods, sewerage system failure and land-slides, or devastating floods, affecting large catchments and having longer duration. In August 2002, due to El Niño effects, a 100-year flood caused by over a week of continuous heavy rains ravaged Europe, killing dozens, dispossessing thousands, and causing damage of billions of Euros in the Czech Republic, Austria, Germany, Slovakia, Poland, Hungary, Romania and Croatia. Prague received significant damage from what were deemed to be the worst floods to hit the capital in 200 years. Most of Prague's art work was saved thanks to advanced warning of high water levels; however there was significant damage to the Prague Metro subway system, much of which was completely flooded. The evacuations before the worst of the flooding have been cited as one of the reasons for relatively little loss of life in the capital. In Germany, Dresden received significant damage when the Elbe River reached the height of 9.4 meters. More than 30,000 people were evacuated from various neighbourhoods throughout the city.

In late July and early August 2002 a series of flash floods occurred in Glasgow where the 19th century storm drain and sewer system present in the East End of the city was surcharged. 
During May, June and August 2010 a devastating series of weather events occurred across several Central European countries (Austria, Czech Republic, Germany, Hungary, Slovakia, Serbia, Ukraine and Poland which was the worst affected). At least thirty-seven people died in the floods and approximately 23,000 people were evacuated.

From the summer of the 2009 to the autumn of the 2011, more than ten floods occurred in Italy causing the death of about fifteen people. In 2009 in the northern Italy, a landslide of seventy thousand of cubic meters came off the Mount Antelao and slipped down killing two people. In the same year in southern Italy, a series of mudflows that swept a great number of homes away occurred due to heavy rains. In 2010, Bacchiglione River and other minor rivers overflowed as a result of heaviest rains and the snowmelt in mountainous area of the catchment. In 24 hours about $550 \mathrm{~mm}$ of rain affected 500,000 people and caused more than 1 million Euros of damage. Nevertheless, the 2011 was the most disastrous year. At least nine people died in flash floods as torrential rains lashed Italy from the Alps to Sicily. Most of the victims were in Borghetto di Vara, a village in the north-western coastal region of Liguria. Waters and mud drove through the village, collapsing at least one building. Floodwaters swept away roads and bridges in some places and several towns in Liguria remained cut off. In Sicily, three people, among that a ten years-old child, died swept away by the mud. In all the presented cases, population preparedness and capacity to face the extreme event had a significant impact on the overall damage.

\section{Flood risk management}

Scientific and technological research provided improved tools for flooding analysis, monitoring and mitigation. Many tools and technologies are currently available even if their application is piecemeal.

In the field of numerical modelling, one-dimensional (1D) hydrodynamic models have been widely used in simulating flood flows. These types of models are computationally efficient for dealing with large and complex river/channel systems and various hydraulic structures. However, when modelling floodplain flows where the 'one-dimensional' assumption is in question, then the accuracy and appropriateness of a 1D model decreases. Quasi two-dimensional (2D) models have been developed for this situation, in which the floodplain is discretised into a network of fictitious river branches and spills linked with main river channels. Although this approach has been successfully used for many flood studies, it is generally time-consuming in setting-up the initial model and the accuracy of predictions varies with the way in which the floodplain is discretised (Leandro et al. [10]). Such models discretise the floodplain according to a regular grid with each floodplain pixel in the grid treated as an individual storage cell. The inter-cell fluxes are treated using uniform flow formulae.

Coupled 1D and 2D models have been developed in recent years and successfully applied to large and complex river systems (Freni et al. [11], Leandro et al. [12]). However, there are still a number of issues with the application of 2D modelling, including a huge difference in the computational 
resource requirements between the $1 \mathrm{D}$ and $2 \mathrm{D}$ models. For example, in modelling flood inundation in an urban area, it was found that the computational time required for a 2D model can be 1000 times higher than that required for a 1D model (Fontanazza et al. [13], Leandro et al. [12]).

The choice between using a 1D surface network model or a $2 \mathrm{D}$ surface system model, depending on the case study and models parameterization, determines the reliability of the results and the computational time required to obtain them (Mark et al. [14]). Simões et al. [15] showed the possibility of integrating 1D/1D models, used for the simulation of the most part of the system, with 1D/2D models, used for the simulation of the flooded area only; such applications are promising because reduce the computational cost of the analysis but still require development for improving the interconnection between such different models.

Recently 1D/2D models have emerged, such as MOUSE-MIKE 21 that couples the 1D MOUSE sewer model with the 2D MIKE 21 overland model (Carr and Smith [16]); Sobek Urban that couples 1D SOBEK flow and 2D Delft FLS (Bolle et al. [17]), or TUFLOW (Phillips et al. [18]); Flood works that combines 1D and 2D modules in the Infoworks framework (Wallingford Software [19]). Modelling computational costs and data demand are the main drawbacks preventing such tools to be applied on a wide scale: the relevant data requirements (in terms of detailed knowledge of urban topography, drainage system topology and characteristics) reduce the number of cases where such approaches are applicable; the high costs limit the interest of small stakeholders that cannot effort the overall cost of the analysis (especially considering the data collection cost).

Further efforts were provided in the collection of data both considering system and catchment characteristics and floodplain extension (also during flood events). Promising results have been provided by remote sensing applications: (Bates [20]) points out that pixel sizes for remotely sensed data are often the same as distributed model element scales and it is often possible to detect hydrologically significant patterns. A great improvement in topographic knowledge was provided by major LiDAR data collection. Programmes are under way in a number of countries, including many countries in EU. In the UK, helicopter-based LiDAR survey is also beginning to be used to monitor in detail $(\sim 0.3 \mathrm{~m}$ spatial resolution) along critical topographic features, such as flood defences, levees and embankments. LiDAR systems operate by emitting pulses of laser energy at very high frequency $(\sim 5-33 \mathrm{kHz})$ and measuring the time taken for these to be returned from the surface to the sensor. Global positioning system data and an on-board inertial navigation system are used to determine the location of the aircraft in space and, hence, the surface elevation. Data can typically be collected at $\sim 1-2 \mathrm{~m}$ horizontal resolution with vertical accuracy of $15 \mathrm{~cm}$ RMSE or less at rates of up to $50 \mathrm{~km}^{2} / \mathrm{h}$. Nevertheless, much further work is required in this area, such studies are beginning to provide methods to calculate important elements of frictional resistance explicitly for particular flow routing problems. This leads to the prospect of spatially distributed grid-scale effective parameters and, hopefully, a reduced need for calibration of hydraulic 
models. If it proves possible to generate flood inundation models with a physically appropriate and more disaggregated discretization of data and model parameters, then we may potentially have a degree of confidence in the spatial predictions made by the particular code. To assess this degree of confidence requires distributed data at a commensurate scale to the model distributed predictions, and in the case of flood inundation models this could be wide-area synoptic maps of inundation extent, water depth or flow velocity. Of these, inundation extent is perhaps the easiest to determine over scales appropriate to flood routing and forecasting problems. Much interest in this area has focused on the use of synthetic aperture radars (SARs) due to their day - night, all-weather capability and high resolution. Satellite SAR data has a resolution of $12.5 \mathrm{~m}$, whilst airborne SAR data may have a resolution down to $0.5 \mathrm{~m}$ and both are of an appropriate scale for hydraulic model validation if the data can be processed to delimit the shoreline accurately. Unfortunately, this may not be straightforward (Horritt and Bates [21]), and such processing tends to be prone to misclassification errors, particularly for satellite data due to the reduced range of frequencies and polarizations available. Yet, such data are at least wide area and distributed and, therefore, have good potential for use in hydraulic model validation. In the future, airborne SAR and wide-area remote measurement of velocity using either microwave Doppler radar or along-track airborne radar interferometry may improve our ability to discriminate between competing models and parameterizations. However, this will undoubtedly raise further questions of how measured state-variable data can be reasonably compared with what a model actually predicts, given that both may be averaged over very different time and space scales.

Another important integration aspect between monitoring and modelling is given by the use of real time forecasting and active feedback from the drainage network (fig. 1). Real-time flood forecast uses a rainfall forecast as input for an online modelling system. This kind of system is based on real-time modelling to forecast the behaviour of the runoff. Warnings are issued when network overflow is forecasted. Additional historical database storage can be done for off-line simulations and data assessment. The main issues for such systems are the forecast accuracy (depending on the rainfall forecast system, on the model calibration...), the update of the model in case of major change and the whole system maintenance. Besides, automatic and continuous calibration process should be considered to ensure the accuracy of the forecast. Active feedback to/from the drainage system operation involves automatic and remote control of the actual network controllable devices based on the model forecast. Remote sensors can provide real time calibration for the numerical models and they are a key technology for such systems because they act as monitoring devices and control devices. The main issue (in addition to the issues for the previous type) is the proper setup of the automatic procedures to ensure that the controlled system will behave efficiently (i.e. to avoid overflows) and safely (i.e. not worst than without control). Whatever the kind of forecasting system, it has to be sustainable and ergonomic. The end-user must have easy access and understanding to the forecast. 


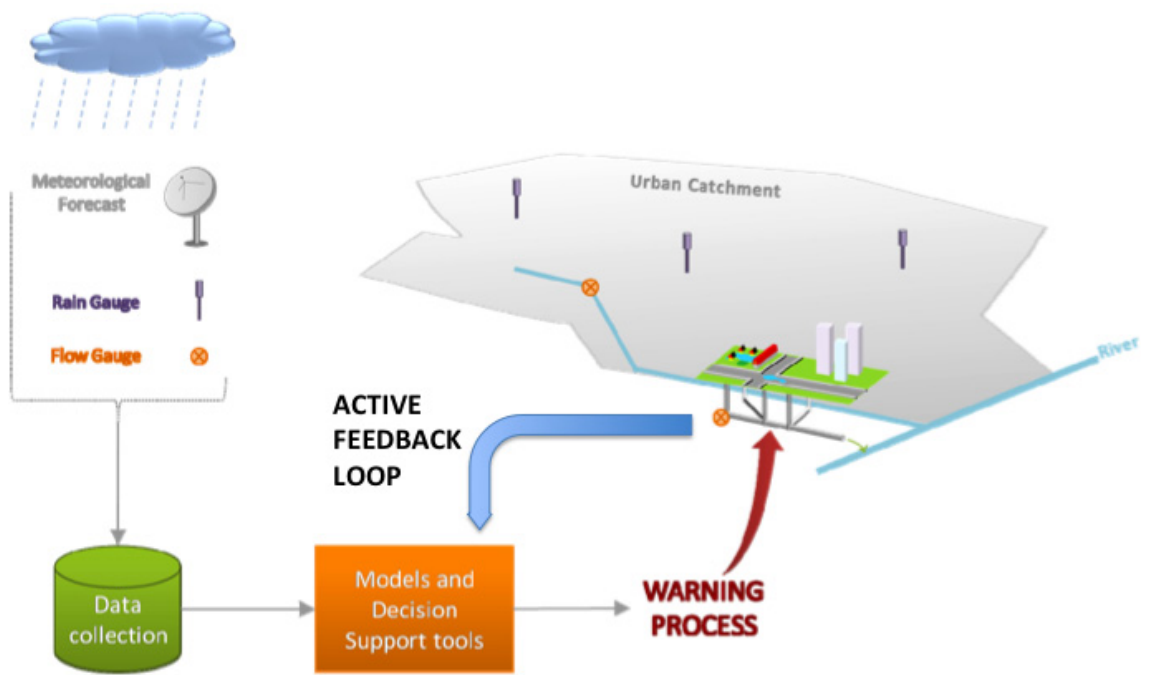

Figure 1: Urban flood forecasting systems with active feedback from/to the drainage system operation.

\section{Towards flood resilient societies}

Scientific and engineering issues above mentioned allow for the development of flood risk management programs that incorporate the prevention of damages caused by floods and the implementation of protection measures.

Apart some problems which may arise in their use and effective spread, namely related to the high costs needed, the social relief is also an important issue in flood risk management. In fact, proactive management of natural disasters and the birth of a flood resilient society require not only risk identification and the development of strategies to reduce that risk, but also preparedness of involved people, that is the need to inform population about flood risks and how to act in the event of a flood. Effective flood warning systems should allow householders sufficient time to remove or relocate valuables and/or evacuate, e.g. by using an automated message service to contact all people on the local flood-warning list by telephone, SMS message or fax to warn them of an impending flood. But after a warning message, citizens should know which are the appropriate actions to take immediately in order to protect their lives and properties.

Some communities (City of Sioux Falls, 2011 Flood Preparedness Information) inform the population by short reports including all information resources (phone numbers and websites to contact) together with detailed tips to prepare before, during, and after floods. The main tips are:

- consider purchasing flood insurance and videotape the property inside and out;

- take steps to flood-proof houses: building tips and Low-Cost Protection Projects to avoid flooding damage; 
- learn the safest route from home;

- keep a portable radio and flashlights in order;

- fill the car with fuel;

- how to build an emergency preparedness kit;

- stay away from flood waters;

- listen to local radio or TV for information;

- do not attempt to drive over flooded roads, because the depth of water is not always obvious;

- if the car stalls in rapidly rising waters, abandon it immediately and climb to higher ground;

- stay away from flood areas;

- stay away from moving water;

- consider health and safety needs such as washing hands frequently with soap and clean water in case of contact with flood waters.

Flood risk education is the first and most important step in creating disaster resilient communities, and new media technologies can be used to manage information. Many websites nowadays promote flood education by mean of movies and other explanation tips $[22,23]$.

In order to promote teaching of flood risk and floodplain management in schools, a Facebook page and Twitter account have been developed (Outreach Process Partners, Oklahoma Floodplain Managers Association, Georgia Association of Floodplain Managers [24]), linked to many pages such as Association of State Floodplain Managers or US National Weather Service.

A commercial product called Stormwater Floodplain Simulation System (WARD'S Natural Sciences [25]) has been realized in the USA. It is a physical model which can be easily assembled, and local Floodplain Management Associations offer free presentations to local schools, because it is important that students and educators gain a new appreciation of the impact of flood events.

Flood scholarship campaigns should also include practices aimed to learn flood proofing techniques, e.g. science project for flood proof houses [26].

The concepts of dry proofing and wet proofing (widely used in the USA) have been superseded in the UK by other definitions. Flood avoidance means constructing a building and its surrounds (at site level) in such a way to avoid it being flooded. Flood resistance means constructing a building in such a way to prevent floodwater entering the building and damaging its fabric. Flood resilience means constructing a building in such a way that although flood water may enter the building its impact is reduced (i.e. no permanent damages caused, structural integrity is maintained and drying and cleaning are facilitated).

Depending on flood depth, and after utilizing options for flood avoidance at site level, designers may adopt different design approaches for flood resilient constructions, as illustrated in the fig. 2. As families and enterprises should improve their ability to deal with the flood, insurance companies should strengthen flood risk control and funds. 


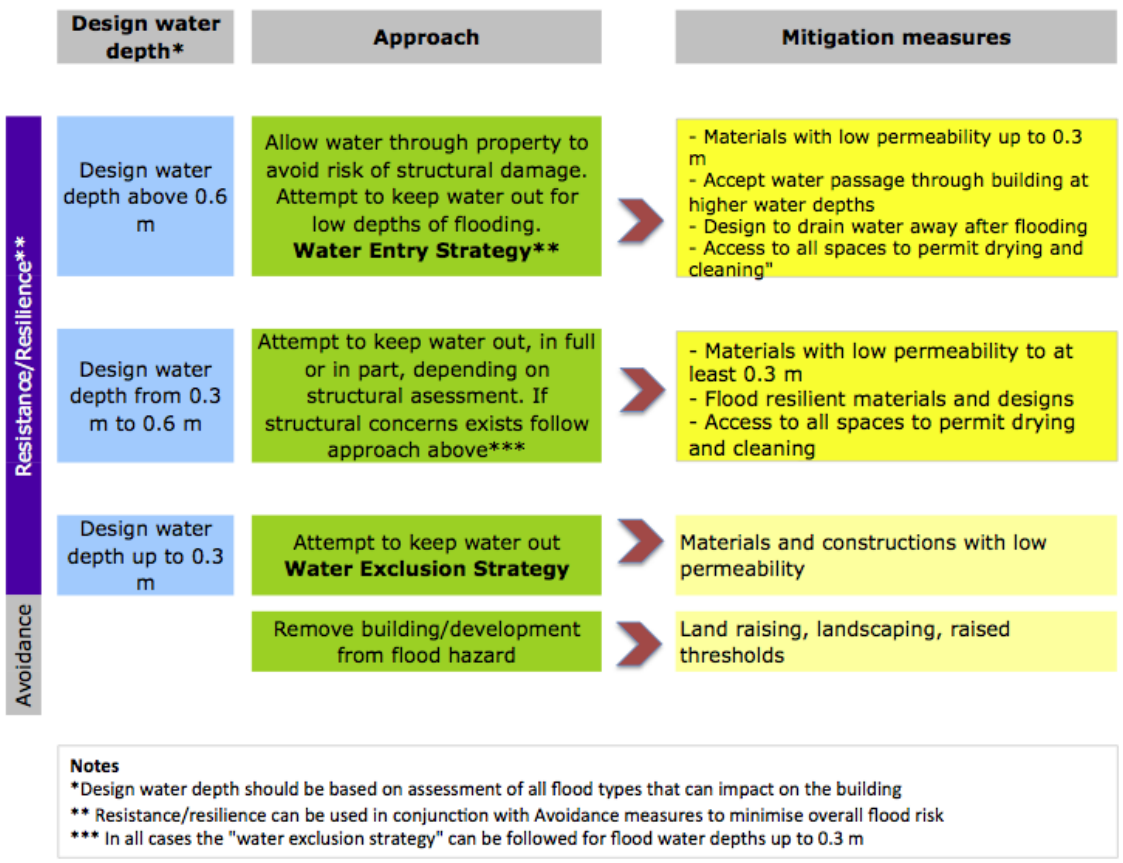

Figure 2: Design approaches for flood resilient constructions (CIRIA [27]).

\section{Conclusions}

According to the above excursus, some general considerations can be drawn about flooding mitigation in existing urbanized areas:

- there is a general need of high resolution data about flooding propagation in urban areas in order to feed detailed hydraulic models and obtain real time information about flooding evolution; such need requires the development of distributed sensor networks (able to collect information about the system behaviour) and the implementation of remote or airborne sensors (in order to have a general picture of flooding evolution);

- models and sensors have to be better integrated in order to allow the direct transfer of monitored data to the model and obtain real time modelling tools;

- real time models and distributed remotely controlled actuators have to be integrated in order to have a rapid response to flooding;

- distributed mitigation plans have to be defined and implemented but population has to be actively involved in the decision, in monitoring and in manage mitigation measures; the creation of a flood resilient society is the first step to increase the effectiveness of structural measures;

- the creation of a flood resilient society can be achieved by public involvement, information and educational programs and it is able, alone, to determine a reduction in flood damage because population is prepared to the flooding 
event; such step increases also the public acceptance of structural measures and allows the progressive adaptation of urban areas to floods.

\section{References}

[1] Novotny, V., A New Paradigm of Sustainable Urban Drainage and Water Management. Proc. of the Oxford Roundtable Workshop on Sustainability, Publications: Oxford University, August 10-15, 2008.

[2] IPCC, Climate Change 2007: The Physical Scientific Basis. Fourth Assessment Report, Intergovernmental Panel on Climatic Change, Working Group (WG 1), Geneva, 2007.

[3] Hill, K., Urban ecological design and urban ecology: an assessment of the state of current knowledge and a suggested research agenda. Cities of the Future: Towards integrated sustainable water and landscape management, eds. Novotny and Brown, IWA: London, 2007.

[4] Ahern, J., Green infrastructure for cities: The spatial dimension. Cities of the Future: Towards integrated sustainable water and landscape management, eds. Novotny and Brown, IWA: London, 2007.

[5] Han, M.Y. \& Park, J.S., Rainwater management in Korea: public involvement and policy development. Proc. of the Rainwater Harvesting Workshop, IWA Rainwater Harvesting Task Force, Marakech, Morocco, 2005.

[6] Grothmann, T. \& Reusswig, F., People at risk of flooding: Why some residents take precautionary action while others do not. Natural Hazards, 38 pp. 101-120, 2006.

[7] Siegrist, M. \& Gutscher, H., Natural hazards and motivation for mitigation behavior: People cannot predict the effect evoked by a severe flood. Risk Analysis, 28(3), pp. 771-778, 2008.

[8] Harvatt, J., Petts, J. \& Chilvers, J., Understanding householder responses to natural hazards: flooding and sea-level rise comparisons. Journal of Risk Research, 14(1), pp. 63-83, 2010.

[9] Price, R.K. \& Vojinovic, Z., Urban flood disaster management. Urban Water Journal, 5(3), pp. 259-276, 2008.

[10] Leandro, J., Chen, A.S., Djordjevic, S. \& Savic, D.A., Comparison of 1D/1D and 1D/2D coupled (sewer/surface) hydraulic models for urban flood simulation. Journal of Hydraulic Engineering, 135(6), pp. 495-504, 2009.

[11] Freni, G., La Loggia, G. \& Notaro, V., Uncertainty in urban flood damage assessment due to urban drainage modelling and depth-damage curve estimation. Water Science \& Technology, 61(12), pp. 2979-2993, 2010.

[12] Leandro, J., Djordjevic, S., Chen, A. S., Savic, D. A. \& Stanić, M., Calibration of a 1D/1D urban flood model using 1D/2D model results in the absence of field data. Water Science and Technology, 64(5), pp. 1016-1024, 2011. 
[13] Fontanazza, C.M., Freni, G., La Loggia, G. \& Notaro, V., Uncertainty evaluation of design rainfall for urban flood risk analysis. Water Science and Technology, 63(11), pp. 2641-2650, 2011.

[14] Mark, O., Weesakul, S., Apirumanekul, C., Aroonnet, S.B. \& Djordjevic, S., Potential and limitations of 1D modelling of urban flooding. Journal of Hydrology, 299(3-4), pp. 284-299, 2004.

[15] Simões, N., Ochoa, S., Leitão, J.P., Pina, R., Marques, A.S. \& Maksimović, C., Urban drainage models for flood forecasting: 1D/1D, 1D/2D and hybrid models. Proc. of the 12th International Conference on Urban Drainage, Porto Alegre, Brazil, 11-16 September, 2011

[16] Carr, R.S. \& Smith, G.P., Linking of 2D and pipe hydraulic models at fine spatial scales. Urban Drainage Modelling and Water Sensitive Urban Design, Monash University: Melbourne, 2006.

[17] Bolle, A., Demuynck, A.; Bouteligier, R., Bosch, S., Verwey, A. \& Berlamont, J. Hydraulic modelling of the two-directional interaction between sewer and river systems. Proc. of the Urban Drainage Modelling and Water Sensitive Urban Design, Melbourne, Australia.

[18] Phillips, B.C., Yu, S., Thompson, G.R. \& de Silva, N., 1D and 2D modelling of urban drainage systems using XP-SWMM and TUFLOW. Proc. of the 10th International Conference on Urban Storm Drainage, DTU, Copenhagen, Denmark, 2005.

[19] Wallingford Software, Infoworks CS, version 7.5, Wallingford, 2006.

[20] Bates, P.D. Remote sensing and flood inundation modelling. Hydrological Processes, 18(13), pp. 2593-2597, 2004.

[21] Horritt, M. \& Bates, P., Effects of spatial resolution on a raster based model of flood flow. Journal of Hydrology, 253(1-4), pp. 239-249, 2001.

[22] http://floodsafety.org/

[23] http://www.weatherwizkids.com/weather-rain.htm

[24] Outreach Process Partners, Oklahoma Floodplain Managers Association, Georgia Association of Floodplain Managers: https://www.facebook.com/ pages/Flood-Risk-Education-in-Schools/

[25] WARD'S Natural Science, Stormwater Floodplain Simulation System 80 W 5770, User's Guide, 2009.

[26] http://www.youtube.com/watch?feature=player_embedded\&v=xf6FwEoll4\#!

[27] Ciria, Improving the Flood Performance of New Buildings - Flood Resilient Construction, 2007. 